\title{
On environment: book review
}

\section{Environment ${ }^{\prime}$}

We usually consider so many things but seldom consider the environment of things, even though the environment is as important as things. The one differs from the other and depends on the other to exist. Without the one, we do not have its other. We can even jokingly say, "Jack of all trades and master of none, because the master is an environment of all trades." "Taking "master" so important as the environment as important," tells of how important the environment is. "But what is the environment?" It is what surrounds things to enable things to be things themselves. The Environment is what "in him, we move, live, and have our being," as Paul says by appealing to his fellow audience, those wise Greeks, without using the word "environment" (Acts 17:28). Paul taking the environment as no less than the supreme God shows again how important the environment is.

A concrete example comes readily to mind. The president of an institution is called "public servant." This custom follows the Master of all masters, Jesus Christ, who served his disciples by washing their feet (John 13). The public servant is universally looked up to by all of us. "Public" is our environment. "Servant" serves the master who actually depends on his servant to survive (Hegel), and so the servant is his master's environment. "Public servant" is then our the environment of our environment. Thus, the environment is ubiquitous, ever supporting us all. In all this, the tiny notion of "in" in the environment is crucially active. On one hand, the environment of things, being so alive, comes on over things to shape things into themselves from their inside, and then such existential shaping spreads all over, so much so that the existential shaping explodes the whole world in sheer beauty. Being an existential surrounding inside things, the environment of things shapes things from their inside to inevitably spread worldwide, world without end.

At the same time, on the other hand, things thus shaped turn around to revise, improve on, and renovate their environment even without their consciously meaning to do so, for they're being themselves is so alive as to spontaneously influence their environment. They being alive cannot help but do so to their inner environment. Our actual polluting of Mother Nature sadly testifies to this sad fact of our ugly returningAll this interactivity, the environment on us, we on the environment, describes the vitality of the "in" in the environment in and of things. Importantly, all this inter-activity happens "in" things inside their environment. Thus the environmental-"in" is a dynamic mutuality of inter-change of inter-transformations between things and their inevitable surrounding of the environment, powerfully erupting inside things. The "in" is an explosive so powerful from inside.

All such "explosion from inside" amounts to things continuing to begin to yet to begin their very existence from inside, all so irresistible, so as to begin to yet to begin the whole wide world. The environment of things constantly begins things from inside to constantly begin the world and exploring the world in sheer novelty alive, to sing the world by each person in each person, without exception. The "in" of the environment explodes into such sight so magnificent indeed. The "in" explodes, and not a single existence can oppose such inner explosion that shapes things to shape the world. Such world-explosion from inside things typifies the inner environment of things so powerful. Typifying the environment this way brings out some typical features

${ }^{1}$ This essay continues my previous ones. The I-Milieus: it's implications for culture and thinking. J World Religions. 2007:1-59 and (II), 2008:1-68.
Volume 3 Issue 6 - 2018

\author{
Kuang-ming Wu \\ Rosebush University Professor in Philosophy emeritus, \\ University of Wisconsin-Oshkosh, USA
}

Correspondence: Kuang-ming Wu, PhD, Rosebush University Professor in Philosophy emeritus University of WisconsinOshkosh, USA, Email knwu2002@yahoo.com

Received: October 04, 2018| Published: November 28, 2018

of the environment. To begin, the environment ever at the beginning to begin things describes the environment as a tender greenhouse for things to grow up into themselves all unbeknown to things themselves. This dynamic environment is often not set and steady but moving as music, to make us intoxicated delirious.

Secondly, intoxicated or not, this environment without our knowing would display an established pattern of social decency, or else open-ended horizons unlimited. Thirdly, the closed or open pattern of environment exercises an influence of education on us. Environment educates. Fourth, we must be educated into Ecopiety toward Mother Nature. Mother Nature must educate us into caring for her to preserve ourselves with our fellow existents. Fifth, in all this, we turn willy-nilly into becoming shapers of our environment natural and socio-cultural, and we as active agents of the environment must consider the what, the how, and the whereto of our shaping. We are now the environment to our environment, whether we like it or not. At least these five features among many others typify the environment that shapes us for us to become environment to shape our environment in return. Now we undergo these five features one at a time.

\section{Music}

When Menuhin's violin sings silence so intoxicating, I swing in it, forgetting me in it. It is a new world alive afresh, compelling in silence so loud. Tender pain seeps in unawares. The world is totally eternal, all endless and indwelling. I am drunk delirious and dizzy. All this while, I continue to sway myself, swinging my head and my heart without ceasing, world without end. Am I sick? I must be sick with sonic beauty, of the magic violin of Menuhin. Fast or slow, slow and fast, I just got carried away far, somewhere unknown, and I do not care, for I do not how to care inside this delirious sonic horizon. When it finally ends, all of a sudden, I wake up, looking around, out of some sort of spell so magical. Have I been swindled, switched with another person, and bewitched away out of myself?

Surely I was far away from myself, which is yet embraced and swung all over eternally - here now. I look around, and Menuhin's violin is found still here now, booming in silence so enticing. Now I feel tender pain in the neck, in my stomach, and all over around me inside me. I must have caught a sort of cold called "Menuhin disease," a dis-ease that is still brewing tender pain all over inside me. I have to get up and walk around for fresh air, which is another silent music of a sort. And then I would perhaps sit down again for another sort of music, a quintet of Bruckner, perhaps. "Perhaps" is repeated because I am not sure. Music makes me not sure of anything. I am a zombie 
whose soul is tricked away by music out of me. Music makes me into a zombie. And then, when that strange Bruckner-beauty sounds again, I am in delirium again in a strange way. Bruckner is a strangely different wine from Menuhin's intoxication. I sway in Bruckner in a different way again, not knowing where I am going. I am only being sure of going somewhere. I am "being" sure because I am being in that situation, moved into that "being" by music. Music moves me without moving me, as you know.

Bruckner is another sort of sonic wine filled with another sort of tender pain delirious. I continue to be drunk this way until I get too tired to continue this way, but "what this way is" is eternally unknown, and I could not care less about my ignorance, either. My ignorance is contained in me all embedded drunk in musical wine, and I am now so drunk and so dizzy that I wobble into sitting down. Music is such a magic of tender wine in tender pain continuous. The magic of music is quite amazing due to its extremely peculiar structure. Music is a peculiar environment. Usually, an environment is a stable context hid implicitly behind explicit activities to support the agent of these activities. Music-as-environment in sharp contrast is quite apparent never hidden, totally explicit never implicit and dynamic throbbing in rhythm, ever moving to actively move us the agents.

In this special environment of music, we the agents are shaken and moved ourselves, for much less than being tacitly supported from behind as usual environment does. As a result, we the agents are embraced and drunk delirious, and dizzied in tender pain, being sick at the stomach. We are rendered soul-sick in music. Music sickens us to the core, even sickens us to near-death but without ever actually dying at all. Music is the sickness unto death that never dies. Such is the intoxicating power of music all invisible and yet absolutely tangible, moving the mountain of the agents. The agents change the objects outside them, without ever changing themselves. Music supports such active agents far much less than positive and actively changing the agents, to wit, moves and transforms the agents themselves who are our total selves. Being moved by the environment called "music," our tacit background now turns into explicit world-devastation in worldtransformation that shakes us the agents to the core.

The agents are active intruders into the world. Music intrudes into these intruders to shake them upside down. Music is the soulrevolution. Music is the soul-shaking transformation of our total self that is by nature the transformers. Music transforms these very transformers. No wonder, we the transforming agents feel sick at the stomach, with tender pain all over and inside out. We so active are now rendered all-helpless inside the music that shakes us heartfelt and soul-total. We are mortally drunk sick, with the sickness unto death that never dies, called "music." Music is my greenhouse alive that begins as my inner environment to throb me through my blood to grow me incoherent rhythm and thereby grows me out of myself to inter-breathe breath to breath with the silent trees. Trees and I now sing reciprocal fresh air to reciprocally keep each other vigorously alive and grow into each other, while we thus antiphonally sing the world. Music is now our outside environment to sing the universe in inter-species symbiosis. The greenhouse has now grown from inner throbbing blood-stream to cosmic and ubiquitous reciprocal breathing, mutually antiphonal and alive in inter-species symbiosis.

Music is shaping me alive. My blood and my breathing so musical come to sing my thinking, my thoughts, and my writing, slowly but surely. Music is my active environment of life in thinking, as this environment continues to shape things that include me myself. Music is thus the life-environment of things whatever. Music throbs incoherent rhythm, so as to throb coherently all things in rhythm. My blood throbs rhythmically to keep me alive. My breathing breathes breathe to breath antiphonally with common trees to keep both these species co-thriving. Personal inter-species symbiosis is enabled and empowered by its shared environment called "music."

\section{Closed or open}

Music is one salient incident of our environment actively shaping us. Environment shapes our modes of activities, even without our consent, and even without our conscious awareness. Conservative economy, for example, is shaped by our conservative and steady environment, while liberal economy appears within an open-ended environment. Something like this deserves elucidating, somewhat as below. Two features appear saliently here: one, the environment is social, two, social environment can be closed-static and also can be open-ended. First, the environment is social. Our intangible and throbbing musical days in society - music is inherently socialsomehow come to regularize themselves and come down on all of us, in eminently visible and tangible ways. Even a tiny baby lives on as she is constantly surrounded by such social environment concocted by humanity. The baby is under pediatric care since before birth, circumcised if born into the Jewish community, washed and powdered, breastfed or bottle-fed, cooed to and stroked over at every moment, and then lullaby-sung into sleep. All such activities in the baby's environment are perpetrated lovingly 24 hours a day and seven days a week.

The baby can never survive for a single moment without being stroked over tenderly and lovingly embraced at every moment, in such social environment definite and all-inclusive. And importantly we must keep in mind that we ourselves are all babies of all ages in absolute need of such enveloping social environment, whether we like it or not. We can never evade this need at all, on pain of perdition.

Fortunately, such need is constantly and ubiquitously satisfied, because nobody would object to being embraced in parental warmth, in which we were all born and are currently being sustained at each moment. Even I now all supposedly grown-up still snuggle up into my dearest Mom and intimate Dad, every time I hit my pillow, all tired out. The societal environment is an indispensable support of my simple survival every single day swaying musically.

Such social environment is quite ubiquitous and iron-clad, in which all of us move, live, and have been. Our environment is called ethos, custom, culture, and even taboos, all of which define inescapably what is decent, what is acceptable, and even what is admirable, and the like, in a specific region. Such environmental definitions define all our ways of living and behaving. We live our specific environment called our cultures. To live human is to be en-cultured in an environment. We live by feeling and behaving in some specific ways, we cannot help it. And these specific ways are our culture as defined by our environment. We live environmentally in culture. Environment composes our life. Surprising as this saying may sound, this statement simply states the brute fact of our human life. The fact is that bereft of the environment that composes a life, life simply vanishes into thin air.

And we must always keep in mind this further fact. It is that there exists no environment-in-general as there is no face-in-general. The Environment is our face, inherently specific, and so the environment is ubiquitously plural and always regional. Each environment differs from all others. The environment is always uniquely my own environment, as you have your own unique environment. And so, 
"environment" is always in a floral form. The environment is "many different environments."Plurality of environment has an ominous result. Usually, I take it for granted that I behave and feel in a specific way since I was born, and so my specific ways of living quite innately mine and are so natural. Thinking this way I continue to live on until I come to meet a different environment, and I am hit with cultureshock. When I first came from my accustomed Taiwan to that strange America, I used to wait for hours standing right there, for my pal said: "See you soon!" I was so shocked that I went upstairs and threw myself into bed, unable to even groan, for even groaning is culturedependent.

I said to my daughter, "My dear, I have been in the USA longer than you have been alive." She then casually said, "But I was born here." That collapsed me at once. I have had culture-shock; she has none. She does not even know what such a strange shock is. She has been living in one cultural environment alone all her life, happily ever after. I, in contrast, have been living long in each of two cultures, one entirely different from the other. I have lived a life quite turbulent. All this while, she has been quite at home in peace, so breezy and halcyon-happy. "Is she lucky?" Well, it depends on how one would deal with such cultural differences so shocking. I happen to have noticed their radical differences, and have carefully dug into their differences, as to what they mean and how to take advantage of these differences to gain a tremendous variety of benefits. Differences can harvest different benefits, as long as we care to notice the differences and ponder on them.

Determination by environment remains quite deep-seated. Believe it or not, my smiles, my frowns, my yawns, even my spontaneous bodysounds, hiccups and sneezes and such, are meticulously regulated by a specific environment, each different from all others. Incredible as it may sound to us anytime, a specific environment is uniquely mine as I belong entirely to my specific environment unique to me. We glibly and confidently say that the missionary must learn from the cultural environment of the region she is going and live, not realizing that all of us are missionaries into specific and respective regions in which we continually live respectively, and the sooner and more carefully we study these environments, the more appropriate and happier we would survive and thrive. Being at home in an environment is to become human happily alive in that specific environment. Cultural anthropology is crucial in this context. Benedict's Patterns of Culture ${ }^{2}$ is our classic guide here. It is actually patterns of the environment as a culture. The book claims that the environment of a culture defines even our ultimate religion and even our basic health. Random and arbitrary trance taken as a pathological abnormality in need of a medical cure in the West is totally revered and worshipped as rare and priceless divine visitation by tribes in Asia. ${ }^{3}$ The environment is allinclusive and all-determining.

Of course, we can courageously dare to defy such tyrannical determination of cultural environment. But we must do so with tact, tastefully and graciously, to survive in our defiance, and taste and grace are defined by the local environment. We must learn from the environment in order to defy the environment at all. The environment is ubiquitous and iron-clad. We have no escape from our environment that socially surrounds us always all over. It is thus that the environment is all-determining yet local, uniquely mine yet ubiquitous, and personal and private yet totally social. The environment is quite

${ }^{2}$ Ruth Benedict. Patterns of Culture (1934). Boston: Houghton Mifflin; 1961. ${ }^{3}$ See ibid. This is her sixth example of this sort. Similar examples of this sort abound in the book so as to render the book so refreshing. p. 265-266. peculiar and entirely inescapable. Any opposition to the environment must be conducted in an environment. The environment is all over all the time. Being all over always is incredible because nothing of the sort exists in the universe of things. Every single thing is limited in time and in space; the limitation is one essential feature constitutive of a thing. Still, we here are concerned not with things but with an environment of things. We just discovered that such environment of things is different from things themselves, and one of the strangely peculiar features of the environment is its ubiquity in time-and-space, and spatiotemporal ubiquity is impossible among things whatever.

Secondly, the social environment can be closed or open. Environment shapes our living engagements so as for us to manage the voluptuous environment under our manageable control, as it were. Such management results in, for instance, a conservative sort of economy that settles in the set and stable status quo, at least for now. This is a harvest of management, on one hand. On the other hand, our management can harvest a liberal sort of economy that literates itself into the future uncertain, indefinite, and even confusing. And even confusion here is exciting, isn't it?

It is thus that two contrary directions among countless environments appear spontaneously, one closed and settled, the other open and soaring. Such contrary appearances demonstrate how dynamic and alive the environment itself is among all its bewildering riches and varieties. Environment involves all such struggles, both playful in open soaring toward infinite horizons and not so playful in settled closure at home. All these struggles are actually excitingly personal and inspiringly ubiquitous. Such a pluralistic environment is much less predictable than jumbles of cacophonous togetherness, reflecting humanity alive and cosmos fabulous, all so chaotic, orderly, and fascinating without ceasing. "Is all this chaotic?" Yes, it is. "Is all this orderly cosmic?" Yes, it is also. The environment is pluralistic, chaotic and cosmic.

To courageously plunge into this antiphonal chaotic order begins our sensitive and sensible management of jumbled status quo. The status quo involves both closures settled at home and open soaring indefinite and delirious. All this while, we do well to keep us intimately familiar with the two contrary types of directions in the bewildering varieties of environment that keeps shaping us ourselves, so as for us to manage well the bewildering environment. This task is inescapable, for being unable to do so is being unable to survive at all. Fortunately, the environment is an enabling power that keeps shaping us up for us to have stamina, persistence, and capabilities enough to manage the environment well.

Obeying our environment obeys our Mother Nature, who then empowers us to manage her in our Ecopiety heartfelt. Obeying Mother Nature empowers us to manage her. We now are empowered to be enabled skillfully and sensitively, to manage our environment adequately well, both as closed settled and as open soaring. As our environment is countless and various, so our management of it continues persistently, variously, and without ceasing. Such description as above presents our days alive within our environment continual. And so, our management of the environment continues likewise, without ceasing so delightful, as our environment keeps us delightfully alive without ceasing, forever vigorous and exciting. Vigorous and exciting to and fro, back and forth, between managing environment and being invigorated by the environment, reciprocate to mutually enhance both our environment and our empowered living. 
Refusing to partake of this enjoyable task of managing our environment, for any reason, simply refuses to survive ourselves, for no reason at all. It is as simple as that, and it is as imperative as simply living on, both closed settled and open soaring. Living in our environment involves managing it into joys of living in the environment. This is because the environment is itself joy vibrant, pure and simple, excitingly open and shut, soaring and settled, all so exciting settled and inspiring soaring, world without end. In the final analysis, we realize. Open adventure puts stress on the beginning, while homing closure put stress on the end. Open adventure launches out, with magnificent potentiality that has the great potency to begin to yet to begin the project. "Well begun, half done," to wit, great beginning commands the result that simply follows the great beginning. All this while, the final closure focuses on the eternal goal of the eternal sovereignty of the Good. It is there that we must repose us at home. All struggles serve this Great End. We can call it Joy, Happiness, Satisfaction, or whatever we can be ultimately satisfied. "All is well that ends well." It is the end that decides the matter.

What shall we say to all this, then? Perhaps we need both the great beginning and the great end. We need both a good start and a good finale. Should we attend to starting well first? Should we aim at the great goal first? But we cannot start at "both starts" from contrary directions. The debate thus goes on. And such continuing debates do little to achieve a substantial solution if "solution" in any sense is viable here. But then, now, we suddenly notice. "Environment" has been smiling at our side all this while in silence. Should we appeal to our environment, then? The environment enables us to begin well, while it reposes poses us at home, assuring us that great goal protects all our struggles and directs them in the right direction. The environment must be our solution to begin well and end well, both at once. How we appeal to our environment is elucidated in three ways, education, eco-piety, and directing environment itself.

\section{Education}

The previous section is concerned with our passive acceptance of the environment shaping us and our management of being shaped. Now here we continue the former section. We advance it by being concerned with our active pursuit and protection of our environment tat that keeps empowering and enabling beings to prosper in Mother Nature. For this purpose, the notion of "education" is taken advantage of advisedly. Precious all over is scholarship that is scholar-hood. Scholar means both one who is learning and one who has learned. So, the scholar is intimately related to education. Education is an activity of our curiosity and dissatisfaction. Our dissatisfaction that inevitably happens in life leads us to insatiable curiosity to know and to learn how skillfully to handle matters.

No wonder "scholarship" in China is "learn-ask," learning in curiosity and asking in dissatisfaction, and learning in dissatisfaction and asking in curiosity, as both are two in one (as education) and one as two (as a scholarship). Education consists in the cultivation of dissatisfaction that provokes us into learning about our Mother Nature and into designing ways of technology to reverently handle Mother Nature and correct our disastrously erratic behaviors out of our disastrous greed. Looking around, we come to be profoundly dissatisfied with our pollutions and destructions of Mother Nature to invite disasters of vast ecological dimension. We are then curious enough to want to learn from Mother Nature about what she is, in natural science. Our science then devises technology to handle our sad pollutions and repair destructions. Our self-wrought disasters provoke us into dissatisfaction about us and curiosity about Mother Nature. Provocation promotes.

All this while, we notice that our conscientious struggles are always supported by Mother Nature who enables us to want to do so and empowers us to do so. We are deeply grateful as we struggle, doing our best to correct our own disastrous performances, which come out of our own greed that is fatal all over. "But we usually end not to do so." If so, our reasonable eco-activities are our command to engage for the promotion of Mother Nature, for us to gratefully thrive in her. Our ecological necessity provokes itself into our life-imperative. This imperative is categorical, to wit, we simply must engage eco-activities, no ifs, and no buts. Education gently transforms things all over on two fronts. On one hand, education changes our own life-attitude, from brutal and bloodies zero-sum game to butcher one another, toward heartfelt win-win management where you win because I win and I win due to you winning. On the other hand, education gently transforms us from greedily taking advantage of Mother Nature, brutally "sucking the blood out" of her, toward caring for our dear Mother Nature and promoting her in loving reverence. And then all things will enjoy educated happiness together, world without end.

An important caution is in order here on education. Education takes place not by external enforcement or authoritative legislation, but naturally by osmosis through the surrounding environment. A legendary story, "Mencius' mother three moves," demonstrates this educative osmosis via the environment. They once lived where pigs were habitually butchered. Baby Mencius soon played killing pigs. Alarmed, his mother moved to the place of funerals. The baby soon played wailing in utmost sorrows. Alarmed again, the mother then moved to the school district, where the baby soon played reading books and discussing matters. Mencius' mother educates us well on how to conduct education. Instead of authoritatively enforcing education that would soon collapse, we must assiduously build up an atmosphere conducive to inducement of learning and enjoyment of studies. Education is by nature an inducement and reducement from inside, via environmental osmosis, never enforcement from outside authority. Outside enforcement only produces authoritarian oppression, never natural reducement that is the essence of education. Dictatorial "education of the people" has consistently failed in history everywhere due to this fatal error. Dictatorship is by nature opposed to natural inducement from inside the life of the people. Education is by nature people-powered, demos-kratia, literally democratic. A dictatorship would never mix with the education of the people from inside, and without education, people would never be induced to "obey" any sort of authority, however "legitimate."

\section{Ecopiety}

"Why do we have to do all this, however?" This is an important query, probing the root of our science and technology to struggle struggling to repair our own disasters in vast ecological dimension. The root of all our anti-eco-disastrous activities lies in our cherishing of existence and reverence of all beings. ${ }^{4}$ We live on Ecopiety. Bereft of Ecopiety we simply die away. The reason is quite simple and straightforward. We are one of those things we hold in reverence. Bereft of reverence of things, we are robbed of our own self-respect, and self-disrespect kills the self. Despising the self, the self is brutalized to death. Now no anger exists at the injustice that violates

${ }^{4}$ Albert Schweitzer's "reverence of life" is a sensitive move, but he is not a thinker. He just advertises, never supplying reasons on why we must do so or how best to do so. 
self-respect. No violence makes sense anymore that used to mean a violation of self-respect. Self-respect is our environment in which we live and have being to be. Without this environment, we just die away. This environment is our Mother Nature in whom we live and have being to be."Reverence for all beings" demands that we do everything we can for all beings to care for them all, to promote their well-being. Reverence for existence performs caring for existence, by examining what we have been doing and revising them, renovating our projects and experimenting on our new approaches, and repeating such performances again and again continually. In such a way as this, existential reverence keeps on readjusting itself to improve on the world at large, so as for our lifeworld to approach the joyous paradise on earth, ever.

We already can see some signs of happiness resulting from our activities of reverence for existence. A small town of Madison in Wisconsin, for instance, has a river going through the campus of the University of Wisconsin there. The river has been thoroughly cleaned up, so much so that people are swimming in it and boating on it, all so happily happy. All automobiles are required to stay at the city limit, registered and parked free. Many city buses are available every five or ten minutes that run through every city street, all campus dormitories, and all classrooms. The buses run on solar energy and electricity. The bus fare is at an absolute minimum if not all free. Everybody can afford to take a bus to freely go around. Naturally, people, there are so happy walking, running, and biking. We do wish and work hard to spread such happiness of a small town all over the whole country. It is easier, of course, to design and actualize small town eco-joys than to produce such lyrical happiness in big cities, but such spread is not impossible, and we are all urged to work on the spread, cornucopia-full, delightfull. Reverence for all beings inevitably results in happiness for all beings. We assiduously work on the spread of such happiness that we all so desire, in eco-gratitude and in existence-reverence.

To put it another way, "blocked, then through," says the Classic of Changes, to wit, nothing cannot can go through one another. This surprising adage is yet quite valid in actuality. Its validity is supported by reverence for all things because such reverence cuts through all things. Reverence is the pivot for all things to go through to and fro, back and forth, quite freely and unobstructed. Such is an ingredient part of what the Classic of Changes displays, the fantastically vast and tightly intricate network of all things in this mundane $\square \square \square$ world and the trans-mundane $\square \square \square$ world (unusual for the practical mentality of China). This fabulous network is empowered and supported by reverence for existence as such. This vast network would have not existed without reverence that cherishes all existents. On a nitty-gritty ${ }^{5}$ strategic front, the Great War expert Sun Tzu proposes what victory in the ultimate sense lies in. Not a single person in world history has ever proposed what "true victory" consists in. He said that the ultimate and genuine victory is to win and capture the heart of our enemies, never to kill them but to win over their heartfelt loyalty. This fantastic ideal of victory would have been unthinkable without reverence for all beings, including our enemies.

All the above points are the incredibly concrete and pragmatic consequences cranked out by reverence for being. Reverence is never vaguely general. Reverence is active, meticulously specific at each moment that comes on continually. Active reverence continues to sing cosmic odes to all harmonies of the spheres, all so concrete, particular, and universal, in reverence for all beings whatever, ever cherishing them all.

${ }^{5}$ Mark McNeilly. Sun tzu and the art of modern warfare. Oxford University Press; 2001

\section{Environment to environment}

The environment is vast and ubiquitous. The ubiquity of the environment is both recursive and reciprocal. The ubiquitous environment is reciprocal in that beings in the environment reciprocally serve as an environment to one another. The ubiquitous environment is recursive in that beings within their environment serve as environment to their environment. We now consider first the reciprocal aspect, and then the recursive aspect, of the environment, as typified by its ubiquity. First, beings within the environment reciprocally serve as environment to one another. We are often accompanied by our babies, for instance. Our baby are is our environment in which we are lifted up and turned baby-fresh and alive, while we who are her caretakers are her environment of tender care on which she depends to survive and grow up. Our babies and we ourselves are an environment to one another, breath to breath. And we are all babies of all ages one to another. Each of us is deserving of cherishing, serving, and promoting one another by one another. We are family members serving as environment one to another. A Confucian sage confesses (Analects 12/5), "Within Four Seas, we are all brethren" of one family of beings, in our shared environment of Mother Nature. Secondly, beings within their environment recursively serve as environment to their environment. We live, move, and have being been within our environment called Mother Nature. Each of us depends on our environment to survive. At the same time, we care for our environment to promote it. We cherish our environment that is our Mother Nature, in hearty reverence. We educate ourselves in our environment by inducing and reducing its promotion with our technology, to clean up the polluted mess we have perpetrated. We thereby promote environmental symbioses all around, by helping endangered species to come back thriving as before with all of us.

And then we suddenly notice. The Beyond-all has been with us all this while, smiling at us and supporting us in our environmental activities. And so, the Beyond is our environment to our reciprocal and recursive environmental activities. The Beyond is the environment to our environment. This super-environment is called Love absolute, unconditional, and ultimate. In addition, it is the nature of love to depend on love to survive as love. Love simply loves to be loved in love. Love invisible is manifested in reciprocal love visible (I John 4:13). Love is the environment ubiquitous always all over. Love is the environment that enables all beings and empowers all beings to serve as an environment to one another, to support one another and thereby thrive together. Thus, whether reciprocally between beings or recursively between beings and their environment, the ubiquity of the environment always implicates "environment to environment." Such mutual environmental support is constant, ultimate, and quite enjoyable, as being together is the supreme joy of coexistence. Environment to environment is constant service that spells joys all ubiquitous. Perhaps not a single person has suspected of assiduous service being capable of harvesting joy. No one would have suspected of service-as-drudgery as service-as-joy. "Joy of service" seems to be a contradiction in terms.

In fact, however, we live on this joy of services to our environment. Our living days consist in of practices of such Ecopiety that is our very life in joy itself. Joys abound all over. Environment ubiquitous that we serve redounds to joys pure and simple to seep into us heartfelt. The environment is an active verb of joy. Environment, love, and joy are three in one. They compose our ultimate trinity that makes up all beings cosmic, individual, and personal. Nothing more can be said. We simply ought to perform such joyous services to the 
environment of our life. Our own life demands such joyous services to our environment

\section{Acknowledgments}

None.

\section{Conflicts of interest}

Author declares there is no conflicts of interest. 